\title{
THE USE OF TRIBOCHARGING IN THE ELECTROSTATIC BENEFICIATION OF LUNAR SIMULANT
}

\author{
S. Trigwell ${ }^{1^{*}}$, J.G. Captain², E.E Arens ${ }^{3}$, J.E. Captain ${ }^{3}$, J.W. Quinn ${ }^{3}$, and C.I. Calle ${ }^{3}$ \\ 'ASRC Aerospace, ASRC-20, Kennedy Space Center, FL 32899, USA \\ *ph: 321-867-1222, e-mail: steven.trigwell-1@ksc.nasa.gov \\ ${ }^{2}$ University of Central Florida, Kennedy Space Center, FL 32899, USA \\ ${ }^{3}$ NASA, Kennedy Space Center, FL 32899, USA
}

Any future lunar base and habitat must be constructed from strong dense materials in order to provide for thermal and radiation protection. Lunar soil may meet this need. Lunar regolith has high concentrations of aluminum, silicon, calcium, iron, sodium, and titanium oxides. Refinement or enrichment of specific minerals in the soil before it is chemically processed may be more desirable as it would reduce the size and energy requirements required to produce the virgin material and it may significantly reduce the process' complexity. Also, investigations into the potential production of breathable oxygen from oxidized mineral components are a major research initiative by NASA.

In this study, the objective was to investigate the use of tribocharging to charge lunar simulants and pass them through a parallel plate separator to enrich different mineral fractions. This technique takes advantage of the high Lunar vacuum in which much higher voltages can be used on the separation plates than in air. Additionally, the Lunar gravity, only being 1/6 that of Earth, allows the particles more separation time between the plates and therefore enhances separation.

For the separation studies, two lunar stimulants were used. The first simulant was created in-house, labeled KSC-1, using commercially supplied (sieved to 325 mesh) materials, and was composed of $40 \mathrm{wt}$. $\%$ feldspar $\left((\mathrm{Na}, \mathrm{K}, \mathrm{Ca}) \mathrm{AlSi}_{3} \mathrm{O}_{8} ; \mathrm{SiO}_{2}\right), 40$ wt. \% olivine $\left((\mathrm{Mg}, \mathrm{Fe})_{2} \mathrm{SiO}_{4}\right), 10$ wt. \% ilmenite $\left(\mathrm{FeTiO}_{3}\right)$, and 10 wt. $\%$ spodumene $\left(\mathrm{LiAlSi}_{2} \mathrm{O}_{6}\right.$ ) (pyroxene). The advantage of the in-house mixture is that the composition can be varied to simulate different soil compositions from different areas on the moon. This simulant was used to show proof-of-concept using the designed separator in air. The second stimulant was JSC-1, used for the vacuum experiments. JSC-1 is principally basalts, containing phases of plagioclase, pyroxene, olivine, and ilmenite. The JSC-1 was sieved to provide a $50-75 \mu \mathrm{m}$ size range to correlate with the mean grain size found on the moon's surface [1].

Four different materials were investigated for the triboelectrification process; aluminum, copper, stainless steel, and PTFE. These materials were selected because they offer a wide variation in work functions (aluminum $4.28 \mathrm{eV}$, copper $4.65 \mathrm{eV}$, stainless steel $5.04 \mathrm{eV}$, and PTFE $5.75 \mathrm{eV}$ ). The difference between the work function of each material and the simulant influences the charge obtained by the grains. Each simulant was analyzed before and after separation using X-ray Photoelectron Spectroscopy (XPS) to determine mineral surface composition. In addition, Raman spectroscopy was performed on the JSC -1 before and after separation in vacuum to determine the mineral composition.

Charge-to-mass $(\mathrm{Q} / \mathrm{M})$ measurements were performed using a fluidizing bed in air and passing the simulant through a static mixer of a particular material and collecting it in a Faraday pail grounded through an electrometer. To measure the $\mathrm{Q} / \mathrm{M}$ in vacuum, a special device was constructed consisting of a heater/shaker cup that fed into a solid block of material (either PTFE, copper, or aluminum) in which a channel composed of a "zig-zag" series of inclines greater than 50 degrees has been cut. The voltage to the vibrating motor can be varied to control the amount of simulant passing through the channel. Figure 1 shows the Q/M measurements for JSC-1 tribocharged using the static mixers and the incline plane chargers in air, and the incline plane chargers in vacuum. 


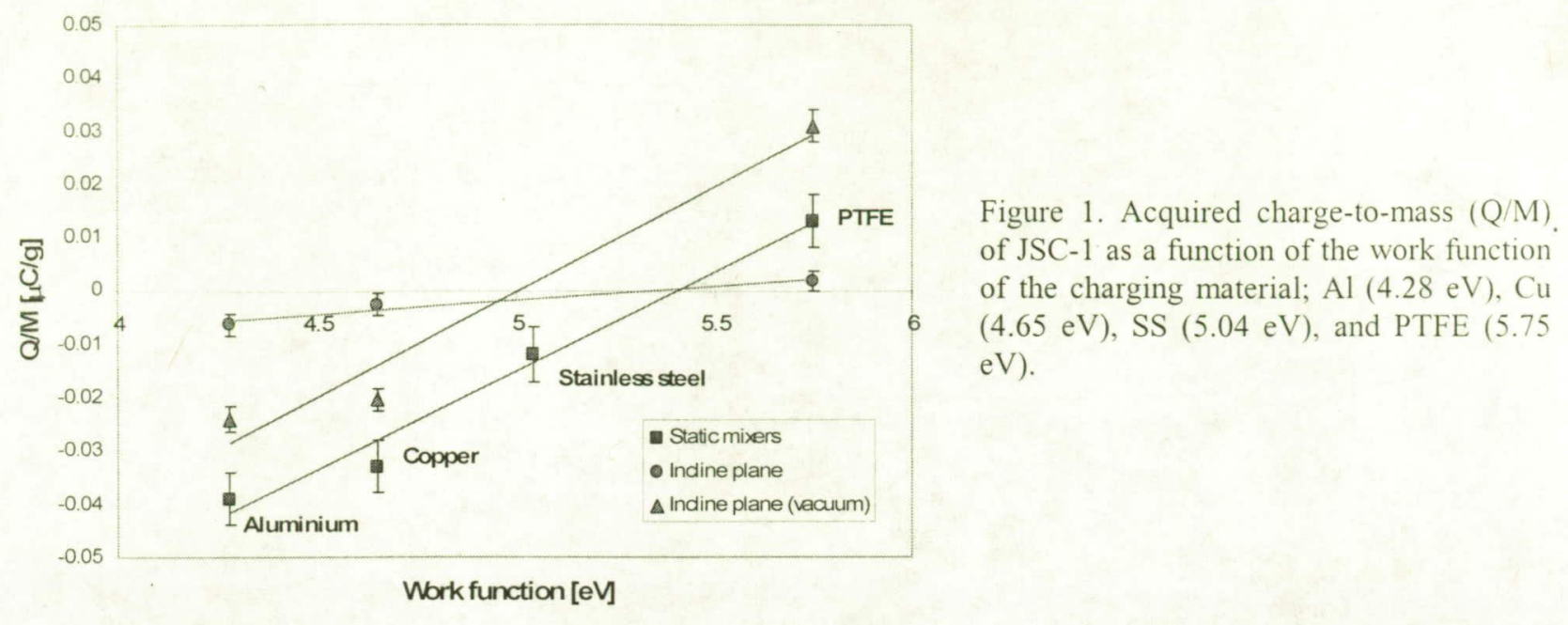

For all chargers, the simulant charged positively against PTFE, while for the three metals, it charged negatively; in direct correlation between the acquired charge on the dust and the work function of the charging material. For the incline plane tribochargers, the $\mathrm{Q} / \mathrm{M}$ measured in vacuum was larger than that in air for the tested materials. The absence of moisture allowed for better charging.

The separation experiments in air using KSC-1 were performed using the stainless steel static mixer. Optical observations of the stimulant after running through the separator showed four distinct shades of grey, from light grey in the collector in the bottom of the separator, to slightly darker greys on the +ve and-ve plates, to the darkest grey for material still left in the static mixer. XPS data of the four fractions when compared to that of the control mixed composition showed significant enrichment of the olivine and spodumene in the bottom tray, and of ilmenite and feldspar in the residual simulant in the static mixer. Both the powder adhered to the +ve and -ve plates showed enrichment in both ilmenite and feldspar, but significantly higher on the -ve plate. It was interesting to note that although both olivine and ilmenite are Fe bearing minerals, they separated differently. The higher concentrations of ilmenite were found in the mixer and on the plates, whereas the olivine was found predominantly in the collector tray. This suggests the olivine charged less than the ilmenite and fell through the plates to the collector tray.

XPS data of the JSC-1 after beneficiation using the aluminum inclined plane charger in vacuum, showed an increase in the Fe concentration on the -ve plate consistent with ilmenite $\left(\mathrm{FeTiO}_{3}\right)$. The Raman data of the control and separated fractions showed ilmenite $\left(\mathrm{FeTiO}_{3}\right)$, anatase $\left(\mathrm{TiO}_{2}\right)$, magnetite $\left(\mathrm{Fe}_{3} \mathrm{O}_{4}\right)$, hematite $\left(\alpha-\mathrm{Fe}_{2} \mathrm{O}_{3}\right)$, ferrite $\left(\mathrm{M}^{2+} \mathrm{Fe}_{2} \mathrm{O}_{4}\right)$, olivine $\left((\mathrm{Mg}, \mathrm{Fe})_{2} \mathrm{SiO}_{4}\right)$, plagioclase $\left(\mathrm{NaAlSi}_{3} \mathrm{O}_{8} / \mathrm{CaAl}_{2} \mathrm{Si}_{2} \mathrm{O}_{8}\right)$, and pseudobrookite $\left(\mathrm{Fe}_{2} \mathrm{TiO}_{5}\right)$. However, in the separated fraction on the negative plate an increased concentration of magnetite and pseudobrookite was observed, whereas on the positive plate predominantly ferrite was observed. However, this is preliminary data and further work is being undertaken.

Further separation experiments in vacuum are planned, including using the copper, stainless steel, and PTFE tribochargers. Multiple passes of the separated fractions through the separator to improve yield as well as experimenting with NASA's new lunar stimulant JSC-1A is also being planned.

[1] Lunar Source Book: A user's guide to the moon, Heiken G. H. (Eds.), (1993) Cambridge University Press, UK. [6] Sternovsky Z. et al. (2002) JGR, 107,15-1 - 15-8. 